Journal of Teacher Education for Sustainability, vol. 20, no. 1, pp. 93-105, 2018

\title{
Making Sense of Core Qualities to Sustain Professional Development through Core Reflection Practice
}

\author{
Bahareh Khazaeenezhad, Mansoor Tavakoli, and Zahra Amirian \\ University of Isfahan, Isfahan, Iran
}

\begin{abstract}
Professional development in sustainable teacher education has recently shifted to focusing on pedagogical practice rather than theoretical knowledge. Given that, reflection practice can have an effective role in identifying undiscovered potentials of prospective language teachers. Hence, the current study was an attempt to examine the potential core qualities of Iranian prospective language teachers in a way to sustain professional development through merging theoretical knowledge and pedagogical practice. To that end, core reflection model, which is a concept in the context of sustainability, was practiced by ten prospective language teachers through drawing on their reflective journals, focus group discussions, and field notes collected over a four month period. Analysis of the obtained data revealed several core qualities on the three scales of feeling, thinking, and wanting. These qualities appeared to have been developed through interaction of both theoretical knowledge and pedagogical practice. This demonstrates the value of reflection practice as a way toward more development in making sense of teachers' core qualities. Thus it can lead to positive changes in shaping teachers sustainable professional identity.

Keywords: sustainable teacher education, professional development, core quality, core reflection
\end{abstract}

\section{Introduction}

Over the next decade, many prospective language teachers will enter the community of language instructors in Iran where there are many candidates for learning foreign languages. The major concern is that these recently graduate teachers, who have gone through theoretical knowledge on campus and have admissible level of theoretical knowledge, know little about pedagogical practice. Studies have shown that the prospective teachers who have recently entered the workplace, more often than not, indicate that knowledge acquired on campus do not enable them to handle the uncertainty, the complexity, and the instability of actual practice situations (Korthagen, Loughran, \& Russell, 2006; Oosterheert, 2001). Unlike many professions, teaching in many countries like Iran is one of careers without a recognized apprenticeship. 
Physicians and surgeons are not asked to make diagnoses or perform operations unsupervised at the end of their classroom training - that supervision is the purpose of internships and residencies. Newly licensed architects are not asked to design a major building during their first week on the job, nor are novice attorneys given the full responsibility for a major case. But a new teacher has the same responsibilities as a veteran with 20 years' experience (Villani, 2002, p. 31).

The claim about these prospective language teachers is that they have undiscovered potentials or core qualities which can be explored through reflection practice as an effective way to develop their professional life. Reflection practice may promote the development of core qualities such as empathy, compassion, love, flexibility, courage, creativity, sensitivity, decisiveness, and spontaneity in prospective language teachers which in turn contribute to fundamental positive changes in language teacher education and guide them toward their sustainable professional identity. Recently, there is increase interest in developing reflective teaching, particularly in teacher education, as reflection on practice leads to increased awareness and effectiveness as a professional practitioner.

The process of reflection in sustainable teacher education is well documented in literature. As Raus and Falkenberg (2014) mention, one critical dimension to look at sustainability in teacher education is to reflect on teachers' identity as the main concept which influences teacher decision making, behavior and action. In addition to the concept of professional identity Rashidi and Meihami (2017) believe that language teacher identity is a vexing issue which cannot be considered as an innate attribute acquired once and for ever.

Schon (1983) provides a conceptualization of reflection upon which many later researchers have based their work. For example, Rodgers (2002) defines reflection as a systematic and disciplined way of thinking that comprises the following phases: spontaneous interpretation of an experience; naming the problem(s) and question(s) that arise out of the experience; generating possible explanations for the problem(s) posed; developing and testing the explanations; and efforts to sort out, or live with, the problem(s) posed. In addition, Korthagen (2005) distinguishes between two concepts: reflection and core reflection. While reflection can be understood as a systematic way of improving one's practice, core reflection involves questioning and reframing a person's deepest levels of functioning such as identity and mission. As Korthagen (2005) points out, core reflection aims at more durable changes in a person in comparison to reflection.

The Core Reflection approach, developed by Korthagen and Vasales (2005), aims at promoting a deep and transformative kind of reflection in coaching teachers. It represents a shift from a focus on problems and deficiencies toward a focus on strengths; What are people's strengths and talents? How can they be used? How can you support people in overcoming obstacles, and help them act upon their strengths or their 'psychological capital'? Core reflection builds on people's 'core qualities' which according to Korthagen (2005) are such qualities as empathy, compassion, love and flexibility. Other examples are courage, creativity, sensitivity, decisiveness, and spontaneity which all aim at overcoming internal and external obstacles to use teachers' best capacities in practice. Core qualities may be constituted as blends or intersections of three elements: thinking (for instance, clarity, creativity, objectivity); feeling (openness, sensitivity, care, compassion), and wanting (strength, commitment, intention, initiative), and can be 
used to explore the authentic self, or the 'real me,' that teachers invest in their work (Korthagen \& Vasalos, 2005). This involves language teachers consciously evaluating and regulating what they are doing when teaching in general, and planning a lesson, managing the classroom, or implementing pedagogical designs in particular.

Consciousness for core qualities contributes prospective teachers to handle the critical situations in real educational setting. As Kukk and Talts (2007) state, contemporary pedagogy presupposes that the teacher has excellent self-knowledge, knowledge on educational reality and his/her profession, readiness to discuss, possesses analytical skills to describe his/her development and is open to upgrading his/her knowledge and skills. Therefore, most of these qualities, which have been valued, indicate sustainability in the teachers' professional development. Directing attention to core reflection during their sustainable professional preparation can help prospective teachers to become more aware of the core qualities of their pupils, so that they will be better able to guide these learners in their learning, and help them to mobilize their core qualities, in school and in their future lives (Korthagen \&Vasalos, 2005). This brings us to an area which has received very little attention from language educators and researchers in language teacher education to the present day.

The focus on core qualities in teachersis the major characteristic of core reflection which is linked to a recent development in psychology called positive psychology. Seligman and Csikszentmihalyi (2000) state that this movement is a reaction to the fact that for too long psychology has focused on pathology, weakness and damage done to people, and hence on 'treatments'. They emphasize that 'treatment is not just fixing what is broken; it is nurturing what is best'. Hence, they stress the importance of positive traits in individuals, which they call character strengths. They mention as examples: creativity, courage, perseverance, kindness and fairness (Peterson \& Seligman, 2003; Seligman, 2002). A central issue in positive psychology is how these strengths mediate between external events and the quality of experience, something that is directly relevant to teacher education. Tickle (1995) also emphasizes that these are essential qualities for teachers. He even maintains that "the teacher as a person is the core by which education itself takes place” (p. 136). Peterson and Seligman (2003) emphasize that character's strengths not only can produce desirable outcomes, but also they can be morally valued in their own right, because "they fulfill an individual". Peterson and Seligman (2003) add that when people are referring to their strengths, this correlates with a feeling of 'this is the real me', that they show 'a feeling of excitement when displaying a strength', and 'a rapid learning curve'.

Since core reflection approach has not been applied to a considerable number of EFL language teaching programs and more specifically to any Iranian contexts yet; the present study may shed some light on this area of language teacher education which has received little or no attention from the researchers and practitioners of the field. Considering the reported effects of reflection in teaching, teacher education and positive psychology, along with the lack of research with regard to the possible role of core reflection approach in language teacher education in Iran, the present study was designed to examine the development of core qualities - strength, commitment, intention, ... which can shape the professional identity of prospective language teachers and guide them toward merging theory and practice in real practice situation. Finally, the present study was designed to incorporate insights from teacher education and positive psychology to provide prospective language teachers with a reflection-based approach to practice 
how to recognize and use their core qualities more optimally in order to overcome teaching obstacles and bring out the best in themselves.

\section{Method}

\section{Research Design}

This study used a qualitative action research approach to integrate theoretical knowledge and pedagogical practice through using core reflection model. This approach reflects a desire to construct a coherent and authentic narrative of prospective language teachers that makes sense of their core qualities. The aims of the study were modestly descriptive in nature, and analysis was qualitative; therefore this study was designed to provide real flavor by building its narrative from descriptions of various data sources rather than by overlaying brief summations with elaborate analysis.

\section{Participants}

Through purposeful sampling, ten participants (two males and eight females) were selected. The selected participants were identified with the following selection criteria: (1) MA undergraduate of TEFL, (2) currently teach general English course to nonEnglish-major students at Sheikhbahaee University, (3) have less than a year of experience in teaching English at university level, (4) acknowledge a concern to integrate on-campus knowledge with pedagogy. The criterion within purposeful sampling is important for selection because it illustrates attributes essential to the study.

Some opportunities were provided for participants involved in the study to: (1) explore their own perspectives on both theory and pedagogy in teaching English, (2) reflect on the practices they bring to the classroom regarding their planning, points of strength and weakness, questions, challenges and troubles (3) familiarize other participants plus the researcher who was a participant observer in focus groups with their experiences.

\section{Instrumentation}

In this study, in order to best explore core qualities of prospective language teachers through using core reflection, focus group discussion, field notes, and participants' reflective journals were used, along with member checking and auditing as ways of ruling out misinterpretation of ideas and boosting the credibility of the results. Attempts were made to use triangulation through utilizing a combination of data collection approaches to complete the process of validating the accuracy of results and increase more consistency. The balance did not necessarily focus on any one of the multiple methodologies or emergent data used to strengthen the study, but provided a deeper understanding into the relationship between the inquiry approach and the studied phenomenon (Patton, 2002). 


\section{Data Collection Procedure}

As the first stage of the study, the selected participants were invited to attend an introduction meeting to be familiarized with the aims and procedures of the study as the vague definition of core reflection for the participants could indeed serve as barriers to them for practicing it. The participants were encouraged to discuss the topic within the introduction meeting in which the researcher further elaborated on the phenomena of core reflection practice. Such effort to develop an authentic understanding of the participants' experiences regarding core reflection practice was very important to develop inquiry that set aside embedded assumptions regarding how this concept might be defined and understood in language teacher education. This was done in order to develop an understanding of how participants perceive and construct their own understanding of what it meant to reflect on their teaching and recognize their core qualities in order to integrate their theoretical knowledge with their pedagogical practice. Then, the participants were asked to keep a reflective journal to reflect on their own practice after each session of teaching general English at Sheikhbahaee University during the semester under study. The reflective journals were shared by the researcher before any focus group discussion in order for the researcher to be able to orchestrate the focus group discussions.

Three focus group discussions were held, at three different dates, at the beginning, middle, and end of the semester. The discussions consisted, mostly, of interactions between the researcher as the observer participant and individual prospective language teachers. Each discussion was audio-recorded and subsequently transcribed by the researcher. At the focus group discussion, prospective language teachers came together to reflect on their teaching practice, and to discuss on their points of strength and weakness and suggest solutions for the problems. The focus group discussions clarified the interpretations emerging within the participants' reflective journals. During and immediately following all discussions field notes were used by the researcher to track information. As the researcher might not clearly recall thoughts and insights that come up during the discussions or when reviewing the data; therefore, field notes were used to highlight such ideas, questions, and insights. This process helped to encourage further description of ideas, thoughts, and interpretations, as well as to highlight further research questions and ideas. After the discussions, field notes were revisited by the researcher to expand on any fragmented ideas or clarify questions or thoughts. The data collected in field notes throughout the discussions were used as a resource to offer a further interpretive stance on what might not have been understood, what was questioned, or what was thought at the time of the discussion.

In an attempt to prevent misinterpretation, after the data was transcribed from the any discussion, each participant had the opportunity to review an electronic copy of their transcripts and verify an accurate portrayal of their comments. Through such member checking process the participants had the opportunity to clarify comments or offer feedback regarding their original responses. Moreover, in order to foster the accuracy and validity of the research study 'auditing' was also used. For the sake of a detailed audit check, a log of all research activities, data collection and analysis procedures along with all data which were collected through using research instruments namely as participants' reflective journals, field notes and focus group discussion transcripts was provided for another researcher who was not involved in the study in order to be examined and reassessed whether the study's findings were grounded in the data and whether the 
inferences were logical.This process of auditing also helped other readers follow each stage of the study and trace through the research logic accordingly.

\section{Data Analysis}

The analysis of the whole data set was guided by grounded theory procedures (Strauss \& Corbin, 1990) and analytical induction techniques (Le Compte \& Preissle, 1993). Analytic induction involves scanning the data for themes and relationships among these themes, and developing and modifying hypotheses on the basis of the data. This was done through hermeneutic cycles of close interpretative readings (Kelchtermans \& Vandenberghe, 1994) of each transcript in order to identify recurrent themes that emerge from prospective language teachers' articulations about their experiences of turning theory into practice within their workplace. In order to extrapolate thematic interpretations, the steps of qualitative data analysis explained by Rubin and Rubin (2005) were used: (1) recognition, (2) examination, (3) coding, (4), sorting, and (5) synthesis. Recognition, examination, and coding were used to prepare the data while sorting and synthesis to analyze the data. In order to locate frequently referenced concepts and themes to clarify meaning and comprehension of the research topic, recognition was implemented, which involved the process of reading, reviewing, and studying the data. When completing the data analysis process, the concepts and themes were combined to tease out insight in relation to the research questions.

Through cross-case analysis, which Patton (2002) describes as a process used to search for patterns and themes that are similar among the experiences of individuals in order to present a holistic picture, all data were coded. The process was actually "an attempt to understand the whole picture of the study" (Janesick, 2004, p. 7). Themes that exist across the experiences of the participants were highlighted and a description of their experiences was emphasized by utilizing direct quotations; however, only those themes that were meaningful and relevant, "substantively significant and providing enough detail and evidence to illuminate and make that case" (Patton, 2002, p. 503). In other words, data were given open-ended and holistic treatment to allow main features to emerge that best answer the research question. Moreover, the participants in the study were invited to read and make comments on the draft of data analysis in the process of member checking as Taylor and Bodgan (1998) claimed 'any interpretation of a social scene will be richer if you have induced members of the scene to comment and react on it'. Moreover, in order to foster the accuracy and validity of the research study 'auditing' was also used. For the sake of a detailed audit check, a log of all research activities, data collection and analysis procedures along with all data was provided for another researcher who was not involved in the study in order for the study's findings and the inferences to be examined and reassessed. Finally, the focus remained on constructing an accurate portrayal of the prospective teachers' perspectives surrounding their understandings of their teaching and their core qualities.

\section{Results and Discussion}

All data of reflective journals, focus group discussions, and field notes were coded to answer the research question. The analysis of transcribed focus group discussions and written reflections along with field notes began by dividing data into units of analysis. 
The unit of analysis was the smallest unit that beard independent meaning from reflection levels point of view. The data were coded thought by thought, one unit of analysis being one understandable thought or idea with a distinct meaning. Conjunctions, irrelevant stretches of discourse and words with no meaning were not coded. Dividing of all data resulted in 550 units of analysis of which 210 were found from reflective journals, 220 from focus group discussion transcripts and 120 from field notes which were all coded accordingly.

As the second step of the analysis all the meaningful units were coded according to the coding scheme of Korthagen \&Vasalos (2005) that was created on the basis of the reflection model. Thereafter, in order to develop a detailed auditing, a log of all research activities, data collection and analysis procedures along with all data which were collected through using research instruments namely as participants' reflective journals, field notes and focus group discussion transcripts was provided for another researcher who was not involved in the study in order to be examined and reassessed whether the study's findings were grounded in the data and whether the inferences were logical. Concurrency of $80 \%$ in units of analysis and $78 \%$ in core qualities was found in $10 \%$ sample of all data log; The result could be considered acceptable as it was a first-time introduction of the coding schema of core qualities based on core reflection model in researching prospective language teachers in Iranian context.

The percentage of all units of analysis has been presented with each category that describes a specific core quality. Core qualities were derived from reflective journals, focus group discussion transcripts and field notes concerning the traits of those prospective language teachers in the study.

The core qualities identified were on three scales: Feeling, thinking and wanting. Feeling, thinking and wanting can be considered fundamental potentials of the human organism (Jarvilehto, 2001). The core qualities of the Feeling scale are expressions of the use of emotions which express interpersonal and social qualities, such as openness, enthusiasm, commitment, trust, care, empathy, compassion and tolerance. Besides, the core qualities of the Thinking scale express the effective use of thinking and cognitive skills to understand the world, and to function on the basis of knowledge and understanding. The items of this scale are creativity, structuredness, clarity, and accuracy. As Korthegan (2005) indicated, when through thinking, a teacher arrives at the rational conclusion that a certain pattern of thinking and acting is counterproductive, and also gains an insight into more constructive possibilities, this may have some influence on the teacher's future behavior. In addition to what mentioned above, the core qualities of the Wanting scale are expressions of the use of will and purpose which represent firmness, decisiveness, perseverance and courage. It is the time when the teacher uses conscious wanting to support his or her own development. In sum, thinking, feeling and wanting are all important in developing professional identity on the basis of core qualities; however, it should be emphasized that actualization of core quality through reflection practice is the key towards professional development specially for prospective teachers who has recently come into touch with their core qualities.

As shown in Table 1, the core qualities on the scale of Feeling derived from journal, focus group discussion transcript and field note are enthusiasm, openness, commitment, and tolerance. 
Table 1

Percentage of Occurrence of Core Qualities on the Scale of Feeling in Reflective Journal, Focus Group Discussion Transcript and Field Note Units

\begin{tabular}{lcccc}
\hline Core quality & Reflective journal & Focus group discussion transcript & Field note & Total \\
\hline Enthusiasm & 43 & 36 & 31 & 35 \\
\hline Openness & 24 & 21 & 27 & 25 \\
\hline Commitment & 19 & 23 & 25 & 22 \\
\hline Tolerance & 14 & 20 & 17 & 18 \\
\hline
\end{tabular}

Enthusiasm is generally recognized as one of the most essential qualities of effective teachers. This core quality has a twofold effect which motivates students to go well beyond the minimum in their achievement and stimulates a kind of trusting relationship. The prospective language teachers in the present study indicated their enthusiasm by instances where they feel fascinated about their teaching and interaction with their students. They made sense of their enthusiasm through growing their passion towards their carrier and constantly developing the pedagogies involved in their students learning. As one of the teachers in this study indicated: I feel really fascinated with the sense of accomplishment when I see my students have developed their skills and are able to communicate through using their second language. At that moment I tell myself "I did $i t$ ". In line with what is believed by this teacher another prospective teacher in this study claimed that: I would like to help my students build their self-esteem in order to believe that everything is possible. I try to teach them how to set their goals as I believe that as a teacher we are responsible to teach beyond the teaching subject.

Another core quality was openness which represents curiosity for trying new things and open-mindedness in accepting others ideas. This quality was the least evident characteristic among the prospective teachers in the study. The reason would be their being too conservative in teaching for the sake of class management or class stability. The teachers indicated that they prefer not to give different things a try but to keep on the same path in order to be able to expect the following events and manage the class. Here there is need for more intervention by the teacher educators to assure the prospective language teachers about the significance of this quality in pedagogical practice. They are required to feel safe and comfortable while making sense of the quality of openness through reflection practice which can enable them to juxtapose different alternatives to realize the most appropriate reaction at the time of unexpected events. With regard to this core quality one of the prospective teachers indicated that: I try to behave as an open-minded person so I allow my students to have comments about my methodology, material and in general my teaching. However, the majority of teachers were worried about losing face in the class, as one of them said: I am always afraid of losing face by mispronouncing a word in my class, I think I need to work on my pronunciation more. In line with the mentioned idea of one of the teachers, another prospective teacher claimed that: I think students get used to the routines of the class, therefore, changing directions and applying new methods of teaching for the sake variety may cause a couple of troubles.

Teacher commitment has been identified as one of the most critical factors for the future success of education and schools (Huberman, 1993). Teacher commitment is another core quality which is an essential element of successful teaching. The prospective language teachers in the present study indicated their commitment by their concern for 
achievement of their students and their quality of their teaching practice. As one of the teachers indicated: We shouldn't overlook the experiential aspect of language learning because it reduces the value of teaching; In my view, to achieve high quality of language education especially in foreign contexts we need both knowledge of use and usage of language. Therefore, we should teach the students the language besides teaching about the language. Such convictions are sometimes very deeply rooted in the mind of the teachers which can easily shape their professional identity.

The prospective teachers mentioned some situations where they tried to cultivate students' curiosity and interest in learning which represent the sense making of teacher commitment and loyalty. The degree of such loyalty of committed teachers can increase if they practice reflecting on their teaching in order to analyze their pedagogical practice to perform their roles more effectively and establish a good teacher-student relationship in accordance with the professional values. For instance, one of the teachers in this study indicated: When I find my students demotivated and frustrated in class, I try to change the atmosphere by telling a joke or making a fun situation.

The last core quality on the scale of feeling in the present study is tolerance. It can also be described as respect and appreciation of the rich diversity of individuals along with their various personality types, learning styles, and forms of expression. The prospective teachers in the present study identified this core quality from two different perspectives; some believed that this not something which can be learnt as a teacher, "you are either a tolerant teacher by nature or not" they expressed. Therefore, they doubted about the significance of reflection practice over such virtue. As one of the prospective teachers indicated: I love teaching and I can cope with it very well; I am very patient and I do not lose my nerve very quickly so I think I was born to be a teacher; I think teaching can improve my character since I learn many things when I am teaching.

The other group indicated tolerance as the quality which makes teachers be able to read and interpret pedagogical situations and students even over their masks. For the second group reflection practice and self development can lead to professional identity in general and tolerance in particular. Reflecting on some incidents in classroom, both groups narrated some instances of being intolerant with students and were enthusiastic about learning some practical solutions for this problem. Discussing intolerance in teaching in focus group discussions, the prospective teacher came to this conclusion that such intolerance is rooted in failure of true perception of students as their real selves besides lack of empathy and openness to signals students send. As Afdal (2005) indicated, tolerance is consideration of students backgrounds, their motives, the particularities of the situations; a tolerant teachers must be perceptive, over-concerned with developed empathy. In line with the mentioned idea, one of the teachers indicated her concern with regard to the quality of tolerance in this way: I think we need to have a clear understanding of our students backgrounds, however, lack of enough time and large number of students in class would not provide such opportunity for us, therefore, moving towards appreciating individual differences is more difficult.

In addition to above mentioned core qualities on the scale of feeling, Table 2 indicates the core qualities on the scale of Thinking derived from journal, focus group discussion transcript and field note ascreativity and clarity. 
Table 2

Percentage of Occurrence of Core Qualities on the Scale of Thinking in Reflective Journal, Focus Group Discussion Transcript and Field Note Units

\begin{tabular}{lcccc}
\hline Core quality & Reflective journal & Focus group discussion transcript & Field note & Total \\
\hline Creativity & 54 & 45 & 40 & 47 \\
\hline Clarity & 46 & 55 & 60 & 53 \\
\hline
\end{tabular}

As Plucker (2004, p. 14) defined "creativity is the interaction among aptitude, process and environment by which an individual or group produces a perceptible product that is both novel useful as defined within a social context". This core quality has a lot to do with professional identity and mission which are the deepest level and the ultimate goal of core reflection practice. For prospective language teachers who have recently finished their studies on campus and entered the workplace, it is quite evident to be proponents of ideas, methods and approaches of others. While this dependency may be helpful at early stages, freezing at this level may be a barrier towards their professional development. Therefore, in order for prospective teachers to develop their own philosophy of education along with the ability to think independently, making sense of creativity is essential.

The prospective teachers in the study reported their attempts to be creative in classroom through using group working, brainstorming, different ways of comprehension checking, and some other strategies; however, the majority of them believed that they were not successful in this regard and do not call themselves as creative teachers. As one of the prospective teachers in this study mentioned: I try my best to merge my theoretical knowledge with my teaching in classroom, however, I think I am not pleased with my attempts. Sometimes I think we got stuck in method era yet and the prescriptive atmosphere and pressure of the educational environment would not let us achieve our potentials.

Analyzing and discussing on the issue in focus group discussions, they identified some blocks which demotivated them from making more attempts to make sense of this core quality. These blocks were of various types made either by social environment, educational setting, students, or the teachers themselves. The conclusion drawn from discussion on this core quality was to practice reflecting on creativity both individually and collaboratively in order to remove the blocks in an effective manner which leads to develop their professional identity.

Teacher clarity is one of the essential core qualities which is defined as a variable which represents a process by which an instructor is able to effectively stimulate the desired meaning of course content and processes in the mind of students through the use of appropriately-structured verbal and non-verbal messages (Chesebro, 1998). Clarity behavior of the prospective teachers in the present study was reflected by the instances of their use of outlines (e.g., "today we will discuss three topics: $a, b$, and c"), transitions (e.g., "now that you have learned present tense, let's turn to past tense"), examples (e.g., "you can use this point in sentences such as..."), definitions (e.g., "this means...."), graphic organizers (e.g. graphs, tables, diagrams, ...), importance markers (e.g., "The point which makes it very important is..."), and summaries (e.g., "today we discussed three topics"). While this core quality is one of the most important skills we can develop in learning how to effectively guide our students to success which help students enjoy the learning process and be better equipped to remember and apply course content, 
instructor clarity cannot be isolated to a single set of behaviors; the concept is multidimensional, including behaviors that span multiple modes of communication that have diverse intended outcomes (Titsworth \& Mazer, 2011). Therefore, rather than devising a set strategy for being clear, instructors are advised to assess students' understanding as a lesson is unfolding and adapt their behaviors as necessary to promote understanding (Titsworth, 2010).

In addition to above mentioned core qualities on the scale of feeling and thinking, Table 3 indicates the core qualities on the scale of wanting derived from journal, focus group discussion transcript and field note asfirmness andgrit.

Table 3

Percentage of Occurrence of Core Qualities on the Scale of Wanting in Reflective Journal, Focus Group Discussion Transcript and Field Note Units

\begin{tabular}{lcccc}
\hline Core quality & Reflective journal & Focus group discussion transcript & Field note & Total \\
\hline Firmness & 48 & 38 & 34 & 41 \\
\hline Grit & 52 & 62 & 66 & 59 \\
\hline
\end{tabular}

One of the common challenges of prospective teachers regarding classroom management is to draw the line between coming off as too kind or too firm. This may cause them having hard time balancing both kindness or firmness in the classroom. This core quality has a significant impact on the behaviors of the students in classroom and is directly related to establishing realistic expectations and consequences involving saying what we mean, and meaning what we say. Students respect and respond well to teachers who demonstrate that they are not easily swayed by student pleas or protests and who treat all students the same regardless of ability, personality, or past experience. As one of the teachers in the study indicated: I really do not know how to react towards those naughty students in classroom; sometimes I want to ask them to leave the class and sometimes I rather leave the class myself. Another teacher mentioned: The behavior of students is the reflection of our behavior in the class, therefore, if we respect them, we will receive care and respect in return.

The prospective language teachers in the present study indicated this core quality through reflecting on the cases when the class was out of control or students did not follow the rules; when they have to use I-messages to show the students that their behaviors were creating discomfort for the teacher or the other students "I expect you to ..."; and when one or some students complain about the lesson, refuse to participate and look upset or angry. They claimed that to be inclined to firmness in the this continuum works more effectively as they can control the students behavior and keep them focused; however, this core quality was discussed comprehensively in focus group discussions to contribute prospective teachers to realize the importance of making balance between firmness and kindness through using some strategies such as ignoring the minor infraction of a rule or a misbehavior of a student in the classroom which is of short duration and does not interrupt the momentum of the lesson.

The second core quality on the scale of wanting is teacher grit which is defined as "passion and perseverance for very long term goals." This could easily be a definition of a successful teacher: When faced with challenges, effective teachers let their passion guide them as they persevere to find the right solutions. The effect of grit on outcomes is through cumulative effort: gritty individuals tend to work harder than their peers, and 
they remain committed to chosen pursuits over a sustained period of time (Duckworth, 2010). Gritty teachers remain in the classroom and work harder, and more deliberately, toward producing academic gains in their students.

The prospective language teachers in the study revealed their grit when they were discussing about their long term goals in teaching; they indicated their concern for merging their theoretical knowledge they learnt on campus with their practice in their classes in order to make best of their potentials. They were not pleased with any specific level of achievement and sense of accomplishment; rather they indicated degrees of ambition and long-term passion which would lead them towards shaping their professional identity. As one of the prospective teachers in the study indicated: I always try to make use of what I learned on campus practically in my classes and I believe that practice can make me a real teacher.

\section{Conclusion}

The present research was aimed to find out the undiscovered potentials or core qualities of prospective language teachers through core reflection practice which leads to positive changes in shaping their sustainable professional identity. The results showed that the core qualities which were derived from reflective journals, focus group discussion transcripts and field notes were classified on three scales of feeling, thinking and wanting which were all essential in developing sustainable professional identity of teachers and contributed to sense making of core qualities. The core qualities identified on the scale of feeling were enthusiasm, openness, commitment and tolerance; the core qualities on the scale of thinking were creativity and clarity; and the core qualities on the scale of wanting were firmness and grit.

In conclusion, utilizing core reflection model in teacher education for prospective language teachers seems to be successful, because the mentioned model fostered sense making of core qualities which would facilitate movement from beginning to professional teacher and contribute to sustainable development of professional identity. This research may highlight the importance of unique individual qualities that prospective language teachers bring to their work. Such practice may recognize teachers as learners too, and claim that the principles of learning through reflection should be encouraged for prospective teachers to be applied to their own sustainable professional learning and identity.

\section{References}

Janesick, V. J. (2004). Stretching exercises for qualitative researchers (2nd ed.) Thousand Oaks, CA: Sage.

Kelchtermans, G., \& Vandenberghe, R. (1994). Teachers' professional development: A biographical perspective. Journal of Curriculum Studies, 26, 45-62.

Korthagen, F., \& Vasalos, A. (2005). Levels in reflection: Core reflection as a means to enhance professional growth. Teachers and Teaching: Theory and Practice, 11(1), 47-71.

Korthagen, F., Loughran, J., \& Russell, T. (2006). Developing fundamental principles for teacher education programs and practices. Teaching and Teacher Education, 22(8), 1020-1041. 
Kukk. A., \& Talts, L. (2007). Teachers' Self Assessment of their Professional Skills According to the Teachers' Professional Standards. Journal of Teacher Education for Sustainability, 8, 14-24.

Le Compte, M. D., \& Preissle, J. (1993). Ethnography and Qualitative Design in Educational Research. New York: Academic Press.

Oosterheert, I. E. (2001). How student teachers learn. Groningen: UCLO.

Patton, M. Q. (2002). Qualitative research \& evaluation methods (3rd ed.). Thousand Oaks, CA: Sage.

Peterson, C., \& Seligman, M. E. P. (2003). Character strengths and virtues: A classification and handbook. New York: Oxford University Press/Washington, DC: American Psychological Association.

Rashidi, N., \& Meihami, H. (2017). Addressing cultural identity through negotiation: Analysis of student-teacher-authored narratives. Journal of Teacher Education for Sustainability, 19(2), 21-32.

Raus, R., \& Falkenberg, T. (2014). The Journey towards a Teacher's Ecological Self: A Case Study of a Student Teacher. Journal of Teacher Education for Sustainability, 16(2), 103-124.

Rodgers, K. B. (2002). Re-framing gifted education: Matching the program to the child. Scottsdale, AZ: Great Potential Press.

Rubin, H. J., \& Rubin, I. S. (2005). Qualitative interviewing: The art of hearing data (2nd ed.). Thousand Oaks, CA: Sage.

Schon, D. (1983). The reflective practitioner: How professionals think in action. New York: Basic Books.

Seligman, M. E. P. (2002). Positivepsychology, positive prevention, and positive therapy. In: C. R. Snyder \& S. J. Lopez (Eds.), Handbook of positive psychology (pp. 3-9). Oxford, etc.: Oxford University Press.

Strauss, A., \& Corbin, L. (1990). Basics of Grounded Theory Methods. Beverly Hills, CA.: Sage.

Strauss, A., \& Corbin, J. (1998). Basics of qualitative research: Techniques and procedures for developing grounded theory (2nd ed.). Thousand Oaks, CA: Sage.

Taylor, S. J., \& Bogdan, R. (1998). Introduction to qualitative research methods: A guidebook and resources (3rd ed.). New York: John Wiley \& Sons.

Tickle, L. (1999). Teacher self-appraisal and appraisal of self. In R. P. Lipka \& T. M. Brinthaupt (Eds.), The role of self in teacher development (pp. 121-141). Albany, N.Y.: State University of New York Press.

Correspondence concerning this paper should be addressed to Bahareh Khazaeenezhad, No.73, 3rd Golestan Alley, Bostan Alley, 1st Apadana St. , Isfahan, Iran. Email: b.khazaeenezhad@gmail.com 